\title{
DESENVOLVIMENTO E QUALIDADE NUTRICIONAL DE MUDAS DE MANGABEIRAS CULTIVADAS EM SUBSTRATOS CONTENDO FIBRA DE COCO E ADUBAÇÃO FOSFATADA ${ }^{1}$
}

\author{
THIAGO JARDELINO DIAS ${ }^{2}$, WALTER ESFRAIN PEREIRA ${ }^{3}$, LOURIVAL FERREIRACAVALCANTE ${ }^{4}$, \\ ROBERTOWAGNER CAVALCANTI RAPOSO ${ }^{4}$, JOSÉ LUCÍNIO DE OLIVEIRAFREIRE ${ }^{2}$
}

RESUMO- Para a produção de mudas de qualidade, é necessária a utilização de substratos com propriedades físicas, químicas e biológicas que condicionem a germinação adequada das sementes e o estabelecimento das mudas. Neste sentido, foi realizado um experimento no Centro de Ciências Agrárias, da Universidade Federal da Paraíba, com o objetivo de avaliar o crescimento e a composição mineral de mudas de mangabeiras (Hancornia speciosa) em substratos compostos por diferentes proporções de fibra de coco (0\% a 40\%), esterco bovino ( $0 \%$ a $25 \%$ ), terra vegetal (25\% a $70 \%$ ) e $15 \%$ de areia, fertilizados com superfosfato triplo (0; 5,5 e $11 \mathrm{~g} \mathrm{dm}^{-3}$ ). A terra vegetal e a fibra de coco exerceram efeitos benéficos às mudas com o aumento de suas proporções no substrato. A adição do esterco e do superfosfato triplo inibiu a produção de matéria seca e a área foliar das mudas. Houve aumento dos teores de nutrientes nas mudas com o aumento da concentração de esterco nos substratos. Pela estimativa dos resultados, o substrato que proporciona maior crescimento e composição mineral mais equilibrada nas mudas de mangabeira deve ser constituído por 14\% de esterco, 56\% de terra vegetal, $15 \%$ de fibra de coco, $15 \%$ de areia e $4 \mathrm{~g} \mathrm{dm}^{-3}$ de superfosfato triplo.

Termos para indexação: Hancornia speciosa, misturas, nutrição mineral.

\section{DEVELOPMENT AND NUTRITIONAL QUALITY OF HANCORNIA SPECIOSA SEEDLINGS CULTIVATED IN MIXTURE CONTAINING COCONUT FIBER AND FERTILIZED WITH PHOSPHORUS}

\begin{abstract}
In order to produce good quality seedlings it is necessary to use a mixture that presents appropriate physical, chemical and biological properties, which supplies the necessary conditions for the germination and the seedling's establishment. This experiment was carried out at the Agricultural Sciences Center, Paraíba Federal University (Brazil), whose objective was to evaluate the growth and the mineral composition of Hancornia speciosa seedlings in substrata composed by concentrations of coconut fiber from $0 \%$ to $40 \%$, manure bovine from $0 \%$ to $25 \%$, soil from $25 \%$ to $70 \%$, sand $15 \%$ and triple superphosphate between 0 and $11 \mathrm{~g} \mathrm{dm}^{-3}$. The soil and coconut fiber had beneficial effects on the $H$. speciosa seedlings with the increase of its concentrations in the mixture. The addition of the manure and the doses of triple superphosphate provoked a decrease in the matter and in the foliate area in the $H$. speciosa seedlings. There was an increase of the nutrients content in the seedlings in which there was an increase of the manure concentration in the mixture. It is recommended to use the concentrations of $14 \%$ of manure, $56 \%$ of soil, $15 \%$ of coconut fiber, $15 \%$ of sand and $4 \mathrm{~g} \mathrm{dm}^{-3}$ of triple superphosphate, for the maximum estimated values of growth and nutritional composition.
\end{abstract}

Index Tterms: Hancornia speciosa, mixture, mineral nutrition.

\footnotetext{
1'(Trabalho 120-08). Recebido em: 14-05-2008. Aceito para publicação em: 25-03-2009.Parte da dissertação do primeiro autor, apresentada ao Programa de Mestrado em Manejo do Solo e da Água, da UFPB, Areia, Paraíba, Brasil.

${ }^{2}$ Eng. Agr. Doutorando do Programa de Pós-Graduação em Agronomia, UFPB/CCA, Campus II, Areia - PB, 58397-000, Areia, Paraíba, Brasil. E-mail: tjardelino@hotmail.com; luciniooliveira@yahoo.com.br

${ }^{3}$ Eng. Agr. Prof. Dr. do Departamento de Ciências Fundamentais e Sociais, UFPB/CCA, Campus II, Areia- PB, 58397-000. E-mail: wep@cca.ufpb.br

${ }^{4}$ Eng. Agr. Prof. Dr. do Departamento de Solos e Engenharia Rural, UFPB/CCA, Campus II, Areia- PB, 58397-000. E-mail: lofeca@cca.ufpb.br; rwcraposo@cca.ufpb.br
} 


\section{INTRODUÇÃO}

A mangabeira (Hancornia speciosa Gomes) é uma frutífera nativa do Brasil, sendo seu fruto bastante apreciado pelas suas excelentes características organolépticas e seu elevado valor nutritivo (Lemos et al., 1989; Vieira Neto, 2001). No entanto, a exploração de uma espécie nativa depende dos conhecimentos técnicos que, em geral, são escassos, havendo a necessidade de pesquisas que viabilizem sua exploração e inserção no mercado (Donadio et al., 2002).

Para a obtenção de mudas de qualidade, fazse necessária a utilização de substratos com propriedades físicas, químicas e biológicas compatíveis com o processo germinativo, crescimento e nutrição mineral da muda. Além disso, a qualidade do substrato depende dos materiais e de suas proporções na composição da mistura (Silva et al., 2001; Nogueira et al., 2003).

A casca de coco, que em muitas regiões causa transtorno ao serviço de limpeza pública pelo volume e por ser de difícil decomposição, vem sendo processada para utilização, pois, além da importância econômica e social, produz uma fibra que pode ser aplicada como substrato de boa qualidade para a produção de mudas (Rosa et al., 2001).

A utilização do fósforo na produção de mudas é indicada por desempenhar função-chave na fotossíntese, além de promover a formação inicial e o desenvolvimento das raízes, aumentando a eficiência da utilização de água pelas plantas, bem como a absorção e a utilização de todos os demais nutrientes (Malavolta et al., 1997; Epstein \& Blomm, 2006).

Quando variáveis de mistura estão envolvidas na otimização dos resultados que dependem da proporção em que esses componentes se encontram, seus níveis não podem ser variados sem levar em conta os outros componentes. Desta forma, misturas são sistemas cujas propriedades dependem das proporções relativas dos seus componentes e não apenas de suas concentrações (Coscione et al., 2005). A técnica de experimentos com mistura tem sido utilizada principalmente em algumas áreas, como na indústria de alimentos (Kim, 2003), na indústria química (Coscione et al., 2005) e nos últimos anos, em pesquisas agrícolas (Bondari, 2005; Beckmann-Cavalcante, 2007).

O trabalho teve como objetivo avaliar o crescimento e a composição mineral em mudas de mangabeira em diferentes misturas de componentes submetidos à adubação fosfatada.

\section{MATERIAL E MÉTODOS}

O experimento foi conduzido no Viveiro de Fruticultura do Departamento de Fitotecnia do Centro de Ciências Agrárias da Universidade Federal da Paraíba (UFPB), no município de Areia-PB. A temperatura e a umidade relativa do ar no período de execução do experimento variaram entre 24 e $32^{\circ} \mathrm{C}$, 60 e $80 \%$, respectivamente.

As sementes foram provenientes de frutos colhidos em plantas selecionadas por via massal, com crescimento vegetativo e estado fitossanitário adequado. Os frutos foram despolpados manualmente para extração das sementes, e estas foram lavadas com água corrente e postas para secar em local ventilado e parcialmente sombreado durante um dia. Em seguida, foram semeadas a $1 \mathrm{~cm}$ de profundidade, em recipientes de polietileno preto, com $15 \mathrm{~cm}$ de largura e $28 \mathrm{~cm}$ de altura, com capacidade para $4 \mathrm{dm}^{-3}$ de substrato.

Os substratos testados foram obtidos pela combinação de esterco bovino ( $0 \%$ a $25 \%$ ), fibra de coco - Goldem Mix Fibroso ${ }^{\circledR}$ (0\% a 40\%), terra vegetal ( $25 \%$ a $70 \%$ ) e $15 \%$ de areia, adubados com 0; 5,5 e $11 \mathrm{~g} \mathrm{dm}^{-3}$ de superfosfato triplo (Tabela 1). Os limites das concentrações dos componentes dos substratos foram obtidos após resultados e questionamentos relatados em trabalhos com mudas de mangabeira, conforme Espíndola (1999), Bezerra \& Rosa (2002), Nogueira et al. (2003) e Pereira et al. (2003), e as combinações foram originadas da aplicação de técnica de experimentos com mistura, através do software Design Expert 6.0 Trial (Stat-Ease Inc., Minneapolis- MN). Foram semeadas quatro sementes por recipiente, tendo sido realizado desbaste e mantida a planta mais vigorosa. O trabalho foi desenvolvido em viveiro coberto com tela de propileno, que proporcionava a redução da radiação solar em $50 \%$.

Os tratamentos foram distribuídos no delineamento de blocos casualizados, com três repetições e quatro plantas por parcela. O experimento foi instalado em novembro de 2004, e aos 150 dias após germinação das sementes foram avaliadas a altura; taxa relativa de crescimento, em altura (TRA); áreas radicular e foliar, e fitomassa da matéria seca da raiz e da parte aérea. Para a mensuração das áreas radicular e foliar, as mudas foram retiradas dos recipientes, para digitalização das imagens, tendo estas sido processadas no software Sigma Scan Pro 5.0 Demo (www.spss.com). A fitomassa da matéria seca da raiz e da parte aérea foram obtidas após acondicionamento das mudas em sacos de papel e secagem em estufa de circulação 
forçada de ar a $65^{\circ} \mathrm{C}$, até atingirem peso constante.

A avaliação da composição mineral dos tecidos foliares das mudas de mangabeira procedeuse analisando os teores totais de macronutrientes (N, P, K), segundo Embrapa (1999). As características químicas dos substratos, conforme Dias et al. (2007), estão detalhadas na Tabela 2. Os resultados foram submetidos à análise de variância e de regressão, apropriada para os experimentos com misturas (Cornell, 2001), considerando até 5\% de significância, pelo teste F. As análises estatísticas foram realizadas com o software Design Expert 6.0 Trial (Stat-Ease Inc., Minneapolis- MN).

\section{RESULTADOS E DISCUSSÃO}

Verificou-se efeito significativo das interações entre esterco bovino, terra vegetal e fibra de coco, como também da terra vegetal, fibra de coco e superfosfato triplo sobre a fitomassa da matéria seca da raiz e da parte aérea das mudas de mangabeira, conforme indicado na Tabela 3 . Observa-se ainda, na Tabela 3, efeito significativo da interação entre terra vegetal, fibra de coco e superfosfato triplo sobre a área foliar, altura e teor foliar de potássio; interação entre esterco bovino, terra vegetal, fibra de coco e superfosfato triplo sobre o teor foliar de nitrogênio; interações entre esterco bovino e superfosfato triplo, terra vegetal e superfosfato triplo, fibra de coco e superfosfato triplo, sobre a taxa relativa do crescimento em altura, e interação entre a terra vegetal e o superfosfato triplo sobre o teor foliar de fósforo.

O esterco bovino, em proporções superiores a $10 \%$ do volume do substrato, inibiu a produção da fitomassa da matéria seca radicular (Figura 1). Esse comportamento pode ser devido à ação de organismos patogênicos que atuaram na fase de plântulas no sistema radicular, comportamento também relatado por Vieira Neto (2001).

A fibra de coco, nas proporções próximas a $30 \%$, e a terra vegetal, nas proporções máximas, apresentaram efeitos benéficos sobre a matéria seca das raízes, evidenciando que proporções adequadas da fibra de coco promovem o aumento da porosidade, contribuindo para o crescimento do sistema radicular, formando raízes finas e compridas, adequadas à fixação das mudas no campo. A terra vegetal, por apresentar características químicas que melhoraram a fertilidade do substrato, provavelmente proporcionou um equilíbrio nutricional adequado para o crescimento da fitomassa da matéria seca radicular.

A utilização de materiais inertes, como a fibra de coco, areia quartzosa ou outros compostos que proporcionam melhoras físicas ao solo, associados à terra vegetal, são componentes adequados na composição de substratos para a produção de mudas de mangabeira (Vieira Neto, 2001).

O aumento das doses de superfosfato triplo diminuiu o efeito da terra vegetal e da fibra de coco sobre a fitomassa da matéria seca radicular, demonstrando que o substrato já atendia às necessidades de disponibilidade de fósforo para a formação da matéria seca radicular. O fósforo pode estimular o desenvolvimento da planta, atuando como nutriente na produção de fitomassa, alocando carboidratos para o aumento da fitomassa da raiz (Lópes-Bucio et al., 2002).

A participação do esterco bovino, assim como na fitomassa das raízes, em proporções superiores a $10 \%$, também reduziu a fitomassa da matéria seca da parte aérea das mudas de mangabeira, em todas as doses de superfosfato triplo aplicadas (Figura 2).

A fibra de coco também apresentou comportamento semelhante ao do esterco bovino, mas na ausência de superfosfato triplo contribuiu para o aumento da fitomassa da matéria seca da parte aérea até atingir valores próximos dos 15\% de proporção. A partir deste ponto, o aumento de sua proporção resultou na diminuição da fitomassa da matéria seca da parte aérea. À medida que foi aumentada a dose da adubação fosfatada, houve diminuição da fitomassa da matéria seca da parte aérea para as proporções iniciais do esterco bovino, entretanto, em proporções na ordem de $20 \%$ do volume do substrato, atingiu valor máximo de matéria seca da parte aérea (Figura 2).

O aumento da proporção de terra vegetal no substrato estimulou a produção da fitomassa da matéria seca da parte aérea até atingir valor máximo de 4,44 g muda $^{-1}$. O aumento das doses de superfosfato triplo provocou a diminuição da matéria seca da parte aérea, de 4,67 para 3,19 g muda $^{-1}$, nas doses de 0 e $11 \mathrm{~g} \mathrm{dm}^{-3}$ de superfosfato triplo, respectivamente (Figura 2). O fósforo pode alterar o desenvolvimento da planta, atuando como nutriente que estimula a produção de fitomassa. Entretanto, alguns autores têm observado efeitos não significativos da suplementação fosfatada aos substratos sobre a matéria seca radicular e aérea, pois os mesmos já continham teores adequados de fósforo para o crescimento das mudas (Nielsen et al., 2001; Fernandez, 2002).

O aumento da proporção de esterco bovino nos substratos, como registrado também para a fitomassa das raízes e da parte aérea, inibiu a expansão foliar das mudas de mangabeira (Figura 3). Este 
comportamento pode ser, em parte, atribuído à ação de patógenos que comprometeram o sistema radicular, fato este evidenciado na retirada das plantas dos recipientes e diagnosticado visualmente, atribuindo as características e os sintomas, como lesão escura no coleto das mudas progredindo para as raízes, provocando o apodrecimento do sistema radicular, causados possivelmente, por agentes patológicos fúngicos, como Cilindocladium clavatum e/ou Fusarium solani, comuns em fases de sementeira e viveiro produtores de mudas de mangabeira (Junqueria et al., 2003; Ferreira \& Marinho, 2007), afetando a absorção de água e nutrientes, e, em consequência, reduzindo a área foliar (Guimarães et al., 2002).

O aumento da proporção de terra vegetal estimulou aumento da área foliar. A adição da fibra de coco e da terra vegetal foi mais eficiente na ausência da adubação fosfatada.

Quanto ao crescimento em altura, registrouse aumento em função da proporção de esterco bovino no substrato (Figura 4). A terra vegetal, nas doses 0 e 5,5 $\mathrm{g} \mathrm{dm}^{-3}$ de superfosfato triplo, aumentou o crescimento das mudas em altura em, aproximadamente, até $45 \%$ na composição do substrato. Apenas na dose de $11 \mathrm{~g} \mathrm{dm}^{-3} \mathrm{de}$ superfosfato triplo foi observado que o aumento da proporção de terra vegetal inibiu o crescimento das mudas de mangabeira em altura.

Constatou-se menor desenvolvimento em altura nas mudas de mangabeira com o aumento da proporção de fibra de coco, sendo mais acentuado com o aumento das doses de superfosfato triplo. A fibra de coco, por apresentar baixa fertilidade, em altas proporções no substrato, prejudicou o crescimento das mudas. A terra vegetal, que apresenta maior potencial de fertilidade e menor capacidade de retenção de água que a fibra de coco, foi mais eficiente no crescimento das mudas.

Os tratamentos que apresentaram a maior taxa de crescimento, corresponderam a aqueles com proporções de esterco bovino inferiores a $20 \%$, refletindo a importância da matéria orgânica no processo de formação das mudas. Resultados semelhantes foram obtidos por Fernandez (2002), recomendando a adubação com esterco bovino e fósforo para a obtenção do maior crescimento em mudas de mangabeira.

A literatura apresenta resultados semelhantes para mangabeira e outras espécies em mudas adubadas com fósforo, conforme Dias et al. (1991) e Venturin et al. (1995); entretanto, essas respostas foram significativas em substratos com teores limitados do nutriente, não se verificando esta situação nos substratos utilizados neste experimento.

O esterco bovino promoveu diminuição da taxa relativa do crescimento em altura (TRA), com o aumento de sua proporção, indicando que o aumento da dose de fósforo influi negativamente no comportamento da fibra de coco (Figura 5). O incremento da proporção de terra vegetal aumentou a TRA, porém foi influenciado pelo aumento da dose de superfosfato triplo, reduzindo este efeito. A fibra de coco apresentou comportamento variável, passando a exercer efeito positivo na dose máxima de superfosfato triplo.

Os teores de nitrogênio na matéria seca foliar foram superiores aos $9 \mathrm{~g} \mathrm{~kg}^{-1}$, considerados adequados à cultura por Silva et al. (1984) e Alves et al.(1989), variando entre 14 e 24 g kg$^{-1}$ (Figura 6). O esterco bovino elevou a acumulação de nitrogênio nas folhas das mudas com o aumento de sua proporção no substrato. Verificou-se, também, a diminuição deste nutriente com o aumento da proporção de fibra de coco e terra vegetal no substrato, sendo a dose $11 \mathrm{~g} \mathrm{dm}^{-3}$, de superfosfato triplo a que proporcionou máximo teor de nitrogênio nas folhas, sendo seguido pelas doses 0 e $5,5 \mathrm{~g} \mathrm{dm}^{-}$ ${ }^{3}$, respectivamente.

Quanto ao fósforo nas folhas das mudas de mangabeira, o esterco promoveu efeito benéfico (Figura 7). A fibra de coco basicamente não interferiu para o aumento do teor de fósforo na fitomassa foliar. O aumento da proporção de terra vegetal promoveu decréscimo do teor de fósforo nas folhas, porém, com o aumento da dose de superfosfato triplo, de 5,5 para $11 \mathrm{~g} \mathrm{dm}^{-3}$ este decréscimo foi menos acentuado. Os teores foliares de fósforo nas mudas de mangabeira foram superiores aos $0,86 \mathrm{~g} \mathrm{~kg}^{-1}$ obtidos por Ferreira et al. (2003).

Com relação aos teores de potássio, constata-se que houve acréscimo com a adição da proporção do esterco bovino e da fibra de coco nos substratos. O aumento da proporção de terra vegetal diminuiu esse teor, pois as mudas estavam nutridas, com teores de potássio variando entre 23 e $38 \mathrm{~g} \mathrm{~kg}^{-1}$ (Figura 8), comparados com os teores encontrados por Almeida (2000) (7,6 $\left.\mathrm{g} \mathrm{kg}^{-1}\right)$ e Espíndola et al. (1998) (22,5 g kg-1).

Os máximos valores estimados referentes ao crescimento vegetativo avaliado, área foliar, fitomassa da matéria seca e taxa relativa do crescimento em altura, bem como para os maiores teores de nitrogênio, fósforo e potássio no tecido foliar das mudas de mangabeira, podem ser obtidos no substrato constituído de $14 \%$ de esterco bovino, 
$56 \%$ de terra vegetal, $15 \%$ de fibra de coco, $15 \%$ de areia e $4 \mathrm{~g} \mathrm{dm}^{-3}$ de superfosfato triplo; provavelmente, essa composição seja mais eficiente para a produção de mudas dessa espécie frutífera nativa (Tabela 4).

TABELA 1 - Composição dos substratos testados, composto por fibra de coco, esterco bovino, terra vegetal e areia, adubados com superfosfato triplo, para a produção de mudas de mangabeira (Hancornia speciosa).

\begin{tabular}{cccccc}
\hline Tratamentos & $\begin{array}{c}\text { Fibra de Coco } \\
(\%)\end{array}$ & $\begin{array}{c}\text { Esterco Bovino } \\
(\%)\end{array}$ & $\begin{array}{c}\text { Terra Vegetal } \\
(\%)\end{array}$ & $\begin{array}{c}\text { Areia } \\
(\%)\end{array}$ & $\begin{array}{c}\text { Superfosfato } \\
\text { triplo }\left(\mathrm{g} \mathrm{dm}^{-3}\right)\end{array}$ \\
\hline 01 & 0,00 & 25,00 & 60,00 & 15,00 & 0,00 \\
02 & 0,00 & 15,00 & 70,00 & 15,00 & 11,00 \\
03 & 0,00 & 25,00 & 60,00 & 15,00 & 11,00 \\
04 & 0,00 & 20,00 & 65,00 & 15,00 & 5,50 \\
05 & 7,50 & 7,50 & 70,00 & 15,00 & 0,00 \\
06 & 15,00 & 0,00 & 70,00 & 15,00 & 11,00 \\
07 & 17,50 & 25,50 & 42,00 & 15,00 & 11,00 \\
08 & 17,50 & 25,50 & 42,00 & 15,00 & 0,00 \\
09 & 22,00 & 14,00 & 49,00 & 15,00 & 0,00 \\
10 & 25,00 & 7,00 & 53,00 & 15,00 & 11,00 \\
11 & 28,00 & 0,00 & 57,00 & 15,00 & 0,00 \\
12 & 35,00 & 25,00 & 25,00 & 15,00 & 11,00 \\
13 & 35,00 & 25,00 & 25,00 & 15,00 & 0,00 \\
14 & 35,00 & 25,00 & 25,00 & 15,00 & 5,50 \\
15 & 40,00 & 0,00 & 45,00 & 15,00 & 0,00 \\
16 & 40,00 & 0,00 & 45,00 & 15,00 & 5,50 \\
17 & 40,00 & 0,00 & 45,00 & 15,00 & 11,00 \\
\hline
\end{tabular}

TABELA 2 - Características químicas dos substratos com diferentes concentrações de fibra de coco, esterco bovino, terra vegetal e areia, adubados com superfosfato triplo, para produção de mudas de mangabeira (Hancornia speciosa).

\begin{tabular}{|c|c|c|c|c|c|c|c|c|c|c|c|}
\hline Trat. & pH & $\mathbf{P}$ & $\mathbf{K}$ & $\mathbf{N a}$ & $\mathbf{H}+\mathbf{A l}$ & Al & $\mathbf{C a}$ & Mg & SB & CTC & M.O. \\
\hline & & \multicolumn{2}{|c|}{-- mg dm ${ }^{-3}$-- } & ----- & ---- --- & \multicolumn{4}{|c|}{ cmol c dm -3 ----- ----- ---- } & & $\mathrm{g} \mathrm{kg}^{-1}$ \\
\hline 01 & 6,8 & 92 & 411 & 0,17 & 0,41 & 0,00 & 4,55 & 2,25 & 8,02 & 8,43 & 31,7 \\
\hline 02 & 6,4 & 284 & 285 & 0,13 & 0,99 & 0,05 & 5,05 & 1,75 & 7,59 & 8,58 & 28,2 \\
\hline 03 & 6,6 & 330 & 473 & 0,24 & 1,16 & 0,00 & 4,75 & 2,05 & 8,25 & 9,41 & 46,8 \\
\hline 04 & 6,8 & 248 & 650 & 0,24 & 0,91 & 0,05 & 8,85 & 2,35 & 10,10 & 11,01 & 41,9 \\
\hline 05 & 5,9 & 82 & 247 & 0,13 & 2,48 & 0,00 & 3,35 & 0,85 & 4,96 & 7,31 & 25,6 \\
\hline 06 & 4,8 & 315 & 258 & 0,12 & 2,48 & 0,15 & 5,35 & 0,95 & 7,08 & 9,56 & 25,0 \\
\hline 07 & 6,4 & 500 & 882 & 0,18 & 2,31 & 0,00 & 6,55 & 1,45 & 10,45 & 12,58 & 40,8 \\
\hline 08 & 6,6 & 232 & 779 & 0,17 & 1,82 & 0,00 & 5,05 & 1,25 & 8,47 & 10,12 & 37,0 \\
\hline 09 & 6,4 & 148 & 650 & 0,19 & 1,32 & 0,05 & 4,75 & 1,85 & 8,45 & 9,77 & 44,6 \\
\hline 10 & 5,4 & 262 & 607 & 0,18 & 3,63 & 0,15 & 5,05 & 1,35 & 8,13 & 11,58 & 39,2 \\
\hline 11 & 5,2 & 143 & 539 & 0,15 & 3,14 & 0,10 & 3,75 & 1,15 & 6,43 & 9,42 & 31,1 \\
\hline 12 & 6,3 & 532 & 1.126 & 0,30 & 2,56 & 0,00 & 7,05 & 0,95 & 11,18 & 13,74 & 63,5 \\
\hline 13 & 6,4 & 287 & 1.160 & 0,29 & 2,06 & 0,00 & 5,65 & 1,95 & 10,86 & 12,92 & 52,1 \\
\hline 14 & 6,5 & 531 & 1.144 & 0,33 & 2,39 & 0,05 & 6,85 & 2,15 & 12,26 & 14,65 & 62,8 \\
\hline 15 & 5,5 & 259 & 851 & 0,17 & 2,39 & 0,05 & 2,35 & 0,75 & 5,45 & 7,84 & 41,9 \\
\hline 16 & 5,1 & 302 & 731 & 0,16 & 2,81 & 0,10 & 3,75 & 1,35 & 7,13 & 9,94 & 35,6 \\
\hline 17 & 5,0 & 306 & 779 & 0,18 & 4,29 & 0,25 & 5,65 & 0,75 & 8,57 & 12,68 & 56,4 \\
\hline
\end{tabular}


TABELA 3 - Equação de regressão para as características avaliadas em função dos componentes esterco bovino, terra vegetal, fibra de coco e superfosfato triplo, em substratos para a produção de mudas de mangabeira (Hancornia speciosa).

\begin{tabular}{|c|c|c|}
\hline Característica & Equação(1) $^{(1)}$ & $\mathbf{R}^{2}$ \\
\hline $\begin{array}{l}\text { Massa da Matéria } \\
\text { Seca Radicular }\end{array}$ & $\begin{aligned} \hat{\mathrm{y}}= & -\quad 0,17 \mathrm{~A}+0 \quad, 02 \mathrm{~B}-0,15 \mathrm{C}+0,0028 \mathrm{AB}+0,00069 \mathrm{AP}+0,0031 \mathrm{BC}-0,0028 \mathrm{CP} \\
& -0,00017 * \mathrm{ABC}+0,00011 * \mathrm{BCP}\end{aligned}$ & 0,92 \\
\hline Massa da Matéria & $\hat{y}=-0,37 A+0,05 B-0,16 C+0,0055 A B+0,01 A C+0,0013 A P+0,0032 B C-0,0031 B P$ & \\
\hline Seca da Parte Aérea & $-0,0017 \mathrm{CP}-0,0002 * \mathrm{ABC}+0,00012 * \mathrm{BCP}$ & 0,90 \\
\hline Área Foliar & $\begin{aligned} \hat{y}= & 2,33^{* *} \mathrm{~A}+1,55 \mathrm{~B}+0,10 \mathrm{C}-0,07 \mathrm{AB}+0,02 \mathrm{AP}-0,16 \mathrm{BC}-0,05 \mathrm{BP}-0,15 \mathrm{CP}+ \\
& 0,0045^{*} \mathrm{BCP}\end{aligned}$ & 0,87 \\
\hline Altura & $\begin{aligned} \hat{y}= & 4,57 * A+1,71 B-2,68 C+0,01 A B+0,0042 A P+0,10 B C-0,01 B P+0,29 C P \\
& -0,0075 * \mathrm{BCP}\end{aligned}$ & 0,93 \\
\hline TRA & $\hat{y}=0,42 A+2,29 B+0,08 C-0,05 * * A P-0,06 * * B P+0,11 * * C P$ & 0,62 \\
\hline $\begin{array}{l}\text { Teor Foliar de } \\
\text { Nitrogênio }\end{array}$ & $\begin{array}{l}\hat{y}=-2,82 A-0,05 B-0,50 C+0,06 \mathrm{AB}+0,09 \mathrm{AC}+0,39 \mathrm{AP}+0,01 \mathrm{BC}+ \\
0,04 \mathrm{BP}+0,22 \mathrm{CP}-0,001 \mathrm{ABC}-0,0087 \mathrm{ABP}-0,01 \mathrm{ACP}-0,006 \mathrm{BCP}+0,0003 * \mathrm{ABCP}\end{array}$ & 0,66 \\
\hline $\begin{array}{l}\text { Teor Foliar de } \\
\text { Fósforo }\end{array}$ & $\hat{y}=0,02 * A+0,004 B+0,01 C-0,0002 A P+0,0005^{* *} B P-0,0002 C P$ & 0,48 \\
\hline $\begin{array}{l}\text { Teor Foliar de } \\
\text { Potássio }\end{array}$ & $\hat{\mathrm{y}}=1,31 \mathrm{~A}+0,38 \mathrm{~B}+0,17 \mathrm{C}-0,02 \mathrm{AB}-0,12 \mathrm{AP}+0,01 \mathrm{BP}-0,004 \mathrm{CP}+0,003 * \mathrm{BC} \mathrm{P}$ & 0,60 \\
\hline
\end{tabular}

${ }^{(1)} \mathrm{A}=$ esterco bovino; $\mathrm{B}=$ terra vegetal; $\mathrm{C}=$ fibra de coco; $\mathrm{P}=$ superfosfato triplo; TRA = taxa relativa do crescimento em altura; *, **: Significativo a $5 \%$ e $1 \%$ de probabilidade, respectivamente, pelo teste $\mathrm{F}$.

TABELA 4 - Combinação ideal dos componentes dos substratos, para a obtenção do máximo crescimento e melhor nutrição mineral para mudas de mangabeira (Hancornia speciosa).

\begin{tabular}{|c|c|c|c|c|c|c|c|c|c|c|c|}
\hline \multicolumn{4}{|c|}{ Componentes } & \multicolumn{5}{|c|}{ Crescimento } & \multicolumn{3}{|c|}{ Teor Foliar } \\
\hline $\mathrm{E}$ & $\mathrm{T}$ & $\mathrm{F}$ & STF & MSR & MSA & $\mathrm{AF}$ & $\mathrm{A}$ & TRA & $\mathrm{N}$ & $\mathrm{P}$ & $\mathrm{K}$ \\
\hline \multicolumn{3}{|c|}{----- \%------ } & $\mathrm{g} \mathrm{dm}$ & $----\mathrm{g} \mathrm{pl}$ & $a^{-1}---$ & $\mathrm{mm}$ planta & $\mathrm{mm}$ planta $^{-1}$ & $\mathrm{~mm} \mathrm{~mm}^{-1}$ & & $-\mathrm{g} \mathrm{k}$ & $b^{-1}--$ \\
\hline 14,0 & 56 , & 15,0 & 4,1 & 2,17 & 4,28 & 68,82 & 209,27 & 126,59 & 17,35 & 0,82 & 31,58 \\
\hline
\end{tabular}

$\mathrm{E}=$ esterco bovino; $\mathrm{T}=$ terra vegetal; $\mathrm{F}=$ fibra de coco; $\mathrm{SFT}=$ superfosfato triplo; $\mathrm{MSR}=$ massa da matéria seca da raiz.; MSA = massa da matéria seca da parte aérea; $\mathrm{AF}$ = área foliar; $\mathrm{A}$ = altura; TRA = taxa relativa do crescimento em altura; $\mathrm{N}$ = nitrogênio; $\mathrm{P}$ = fósforo; $\mathrm{K}$ = potássio. 

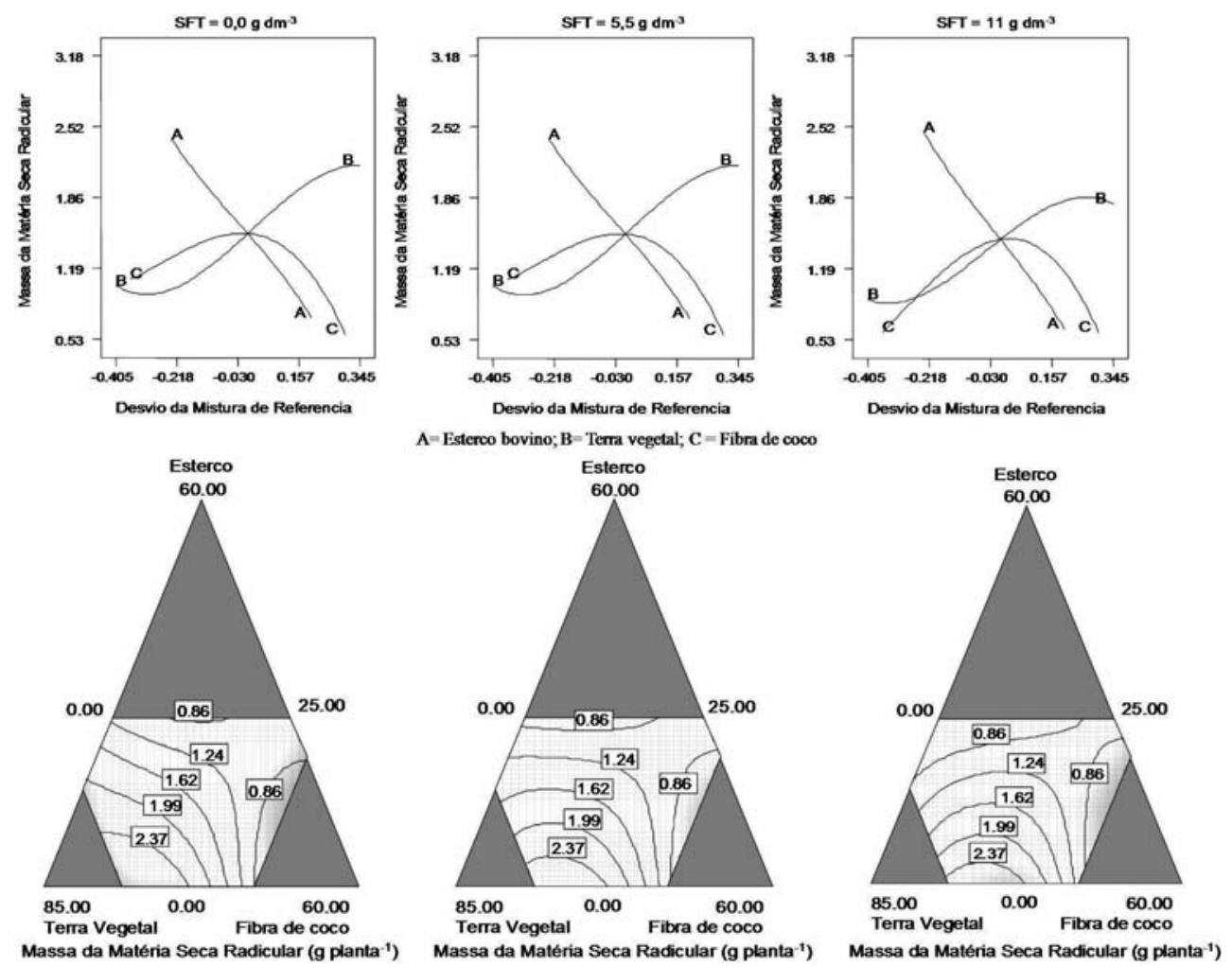

FIGURA 1 - Massa da matéria seca do sistema radicular das mudas de mangabeira (Hancornia speciosa) em função dos diferentes componentes dos substratos.
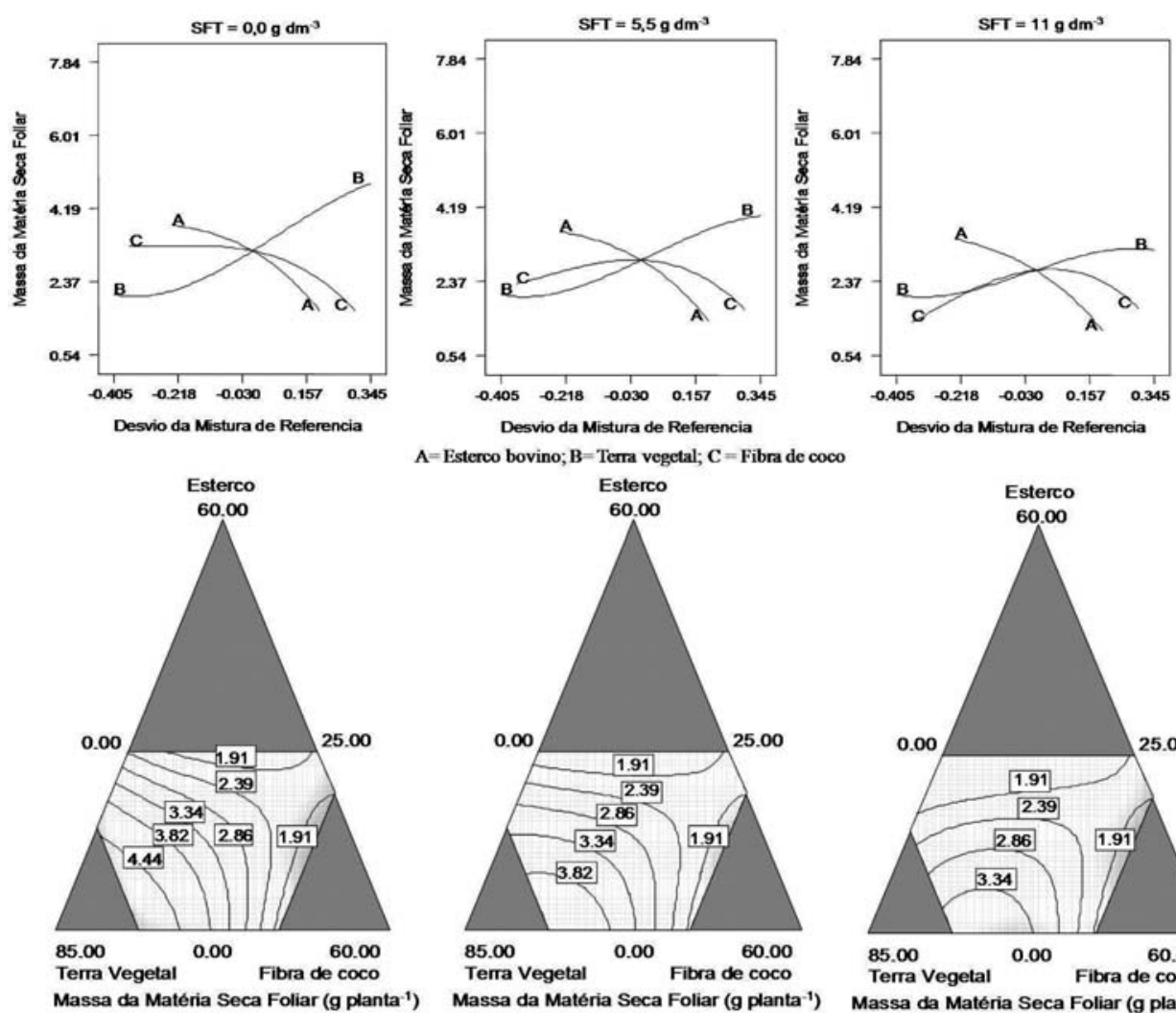

A=Esterco bovino; $\mathbf{B}=$ Terra vegetal; $\mathbf{C}=$ Fibra de coco

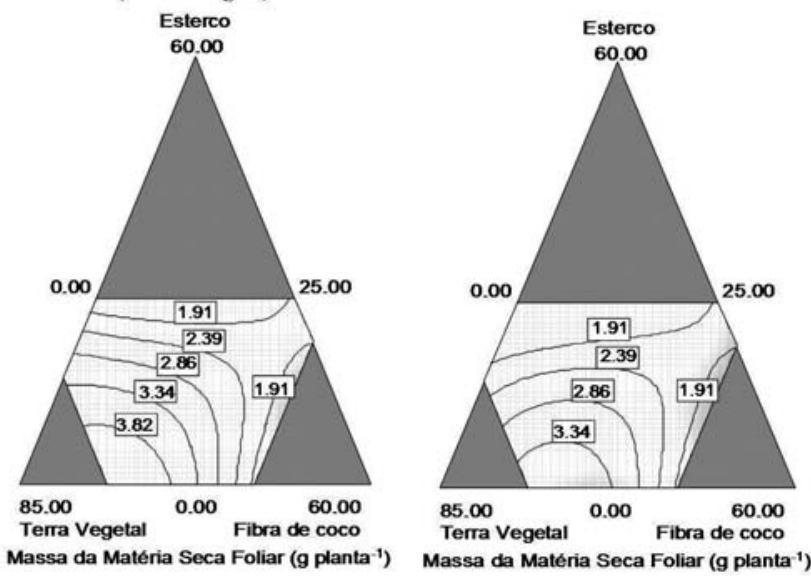

FIGURA 2 - Massa da matéria seca da parte aérea das mudas de mangabeira (Hancornia speciosa) em função dos diferentes componentes dos substratos. 

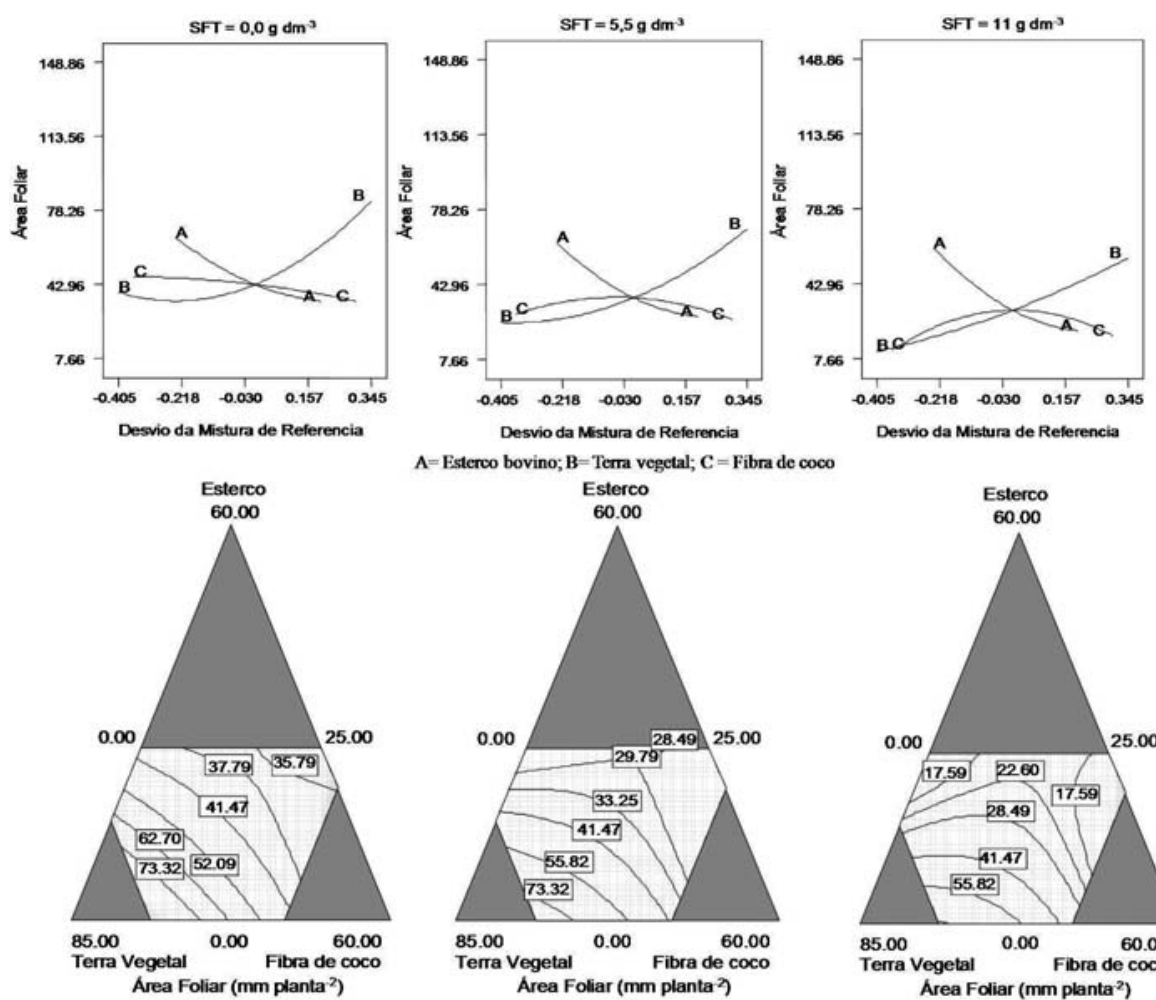

$\mathbf{A}=$ Esteroo bovino; $\mathbf{B}=$ Terra vegetal; $\mathbf{C}=$ Fibra de coco
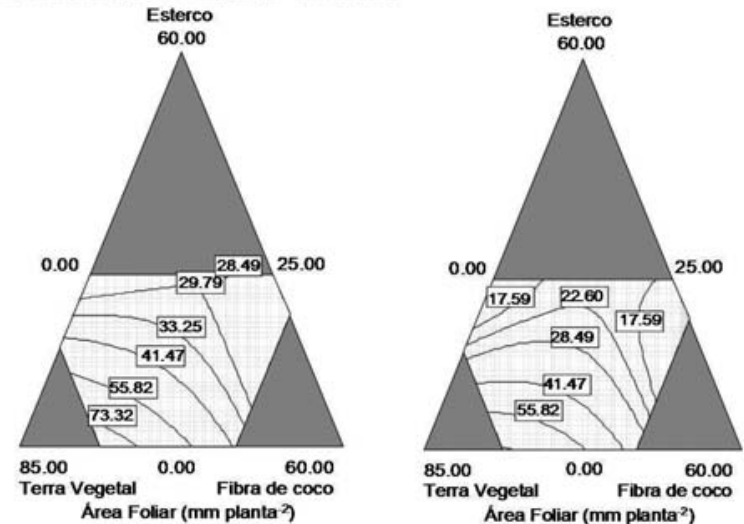

FIGURA 3 - Área foliar das mudas de mangabeira (Hancornia speciosa) em função dos diferentes componentes dos substratos.
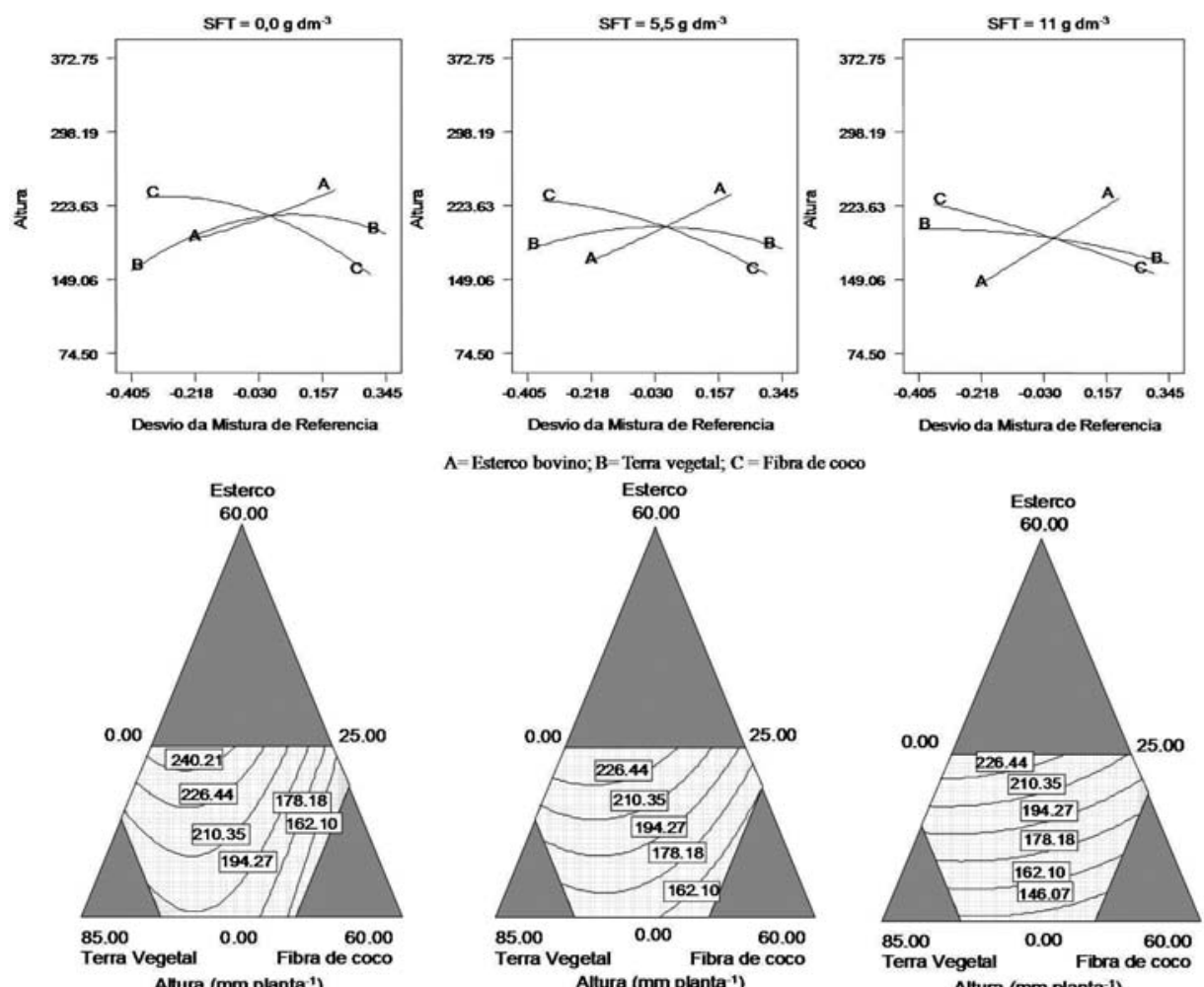

A= Esterco bovino; B $=$ Terra vegetal; C $=$ Fibra de coco
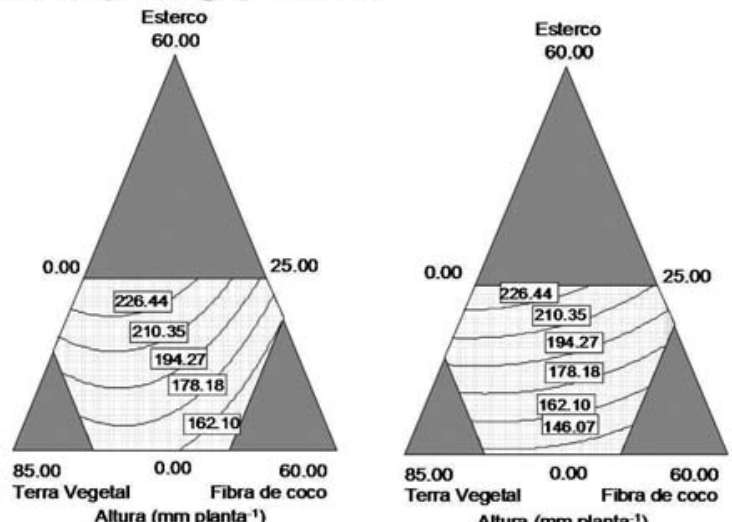

FIGURA 4 - Altura das mudas de mangabeira (Hancornia speciosa) em função dos diferentes componentes dos substratos. 

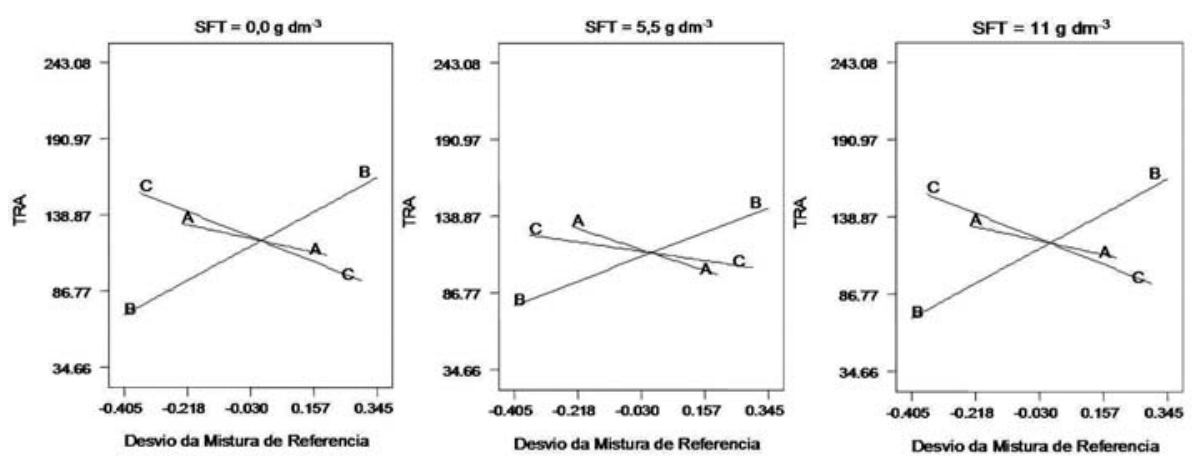

A=Esteroo bovino; B-Terra vegetal; C = Fibra de coco
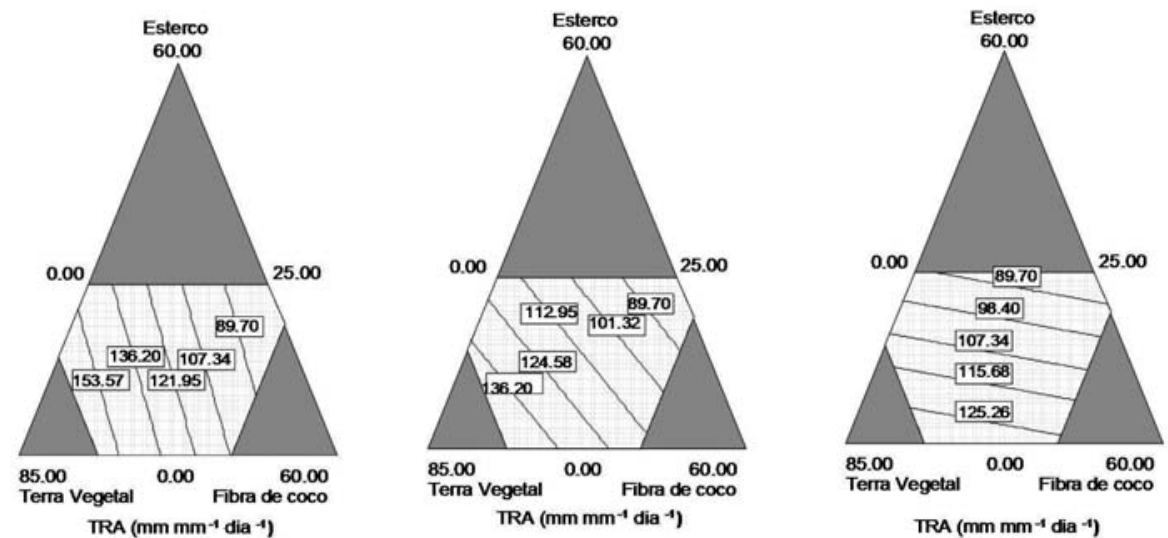

TRA ( $\mathrm{mm} \mathrm{mm}^{-1}$ dia -1$)$

FIGURA 5 - Taxa relativa do crescimento da altura (TRA) das mudas de mangabeira (Hancornia speciosa) em função dos diferentes componentes dos substratos.
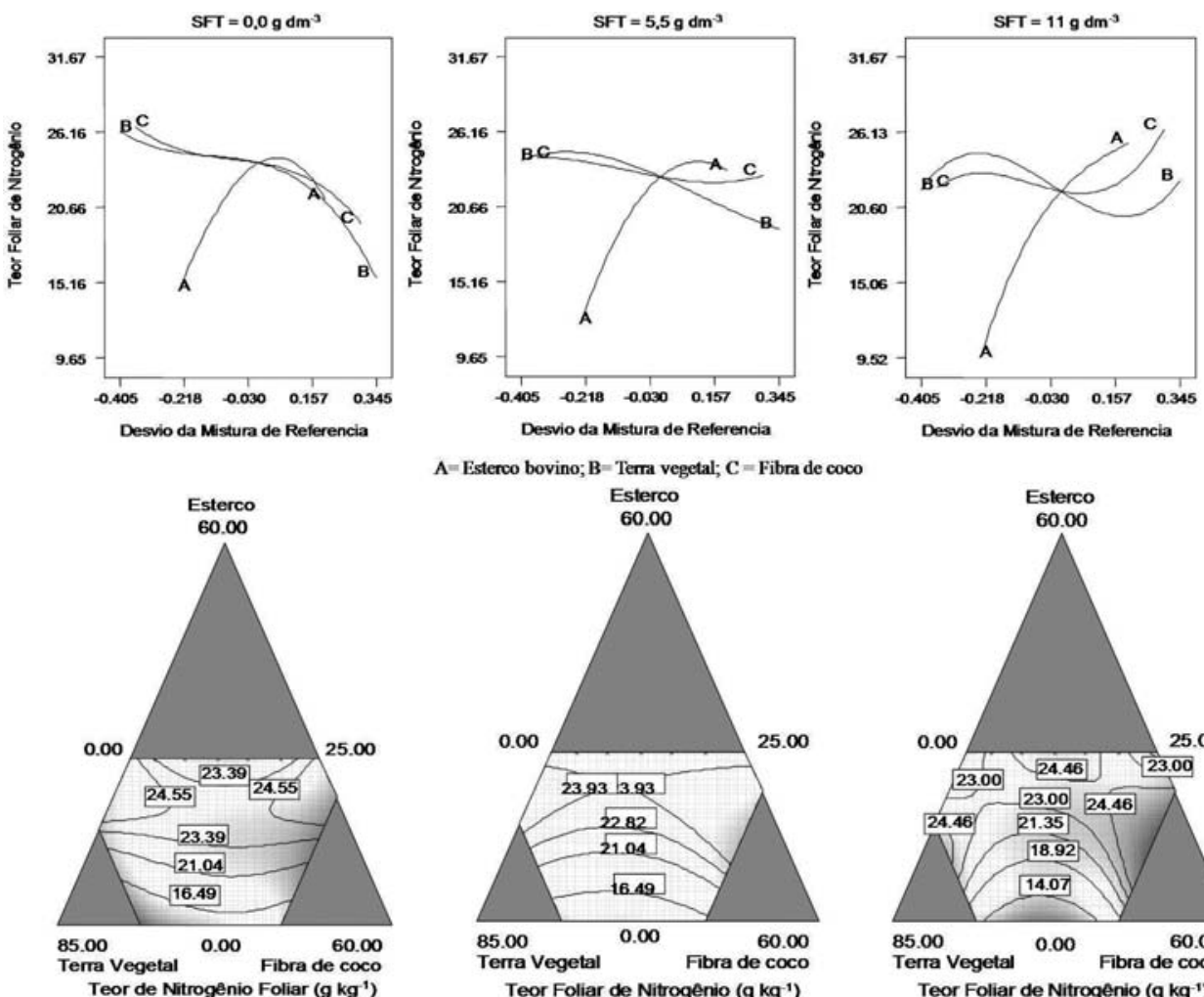

A= Esterco bovino; $B=$ Terra vegetal; $\mathbf{C}=$ Fibra de coco
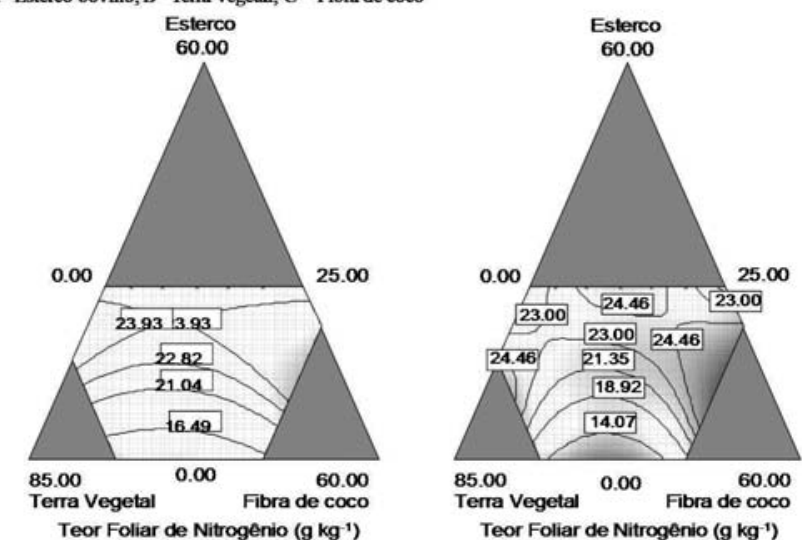

FIGURA 6 - Teor de nitrogênio nos tecidos foliares das mudas de mangabeira (Hancornia speciosa) em função dos diferentes componentes dos substratos. 

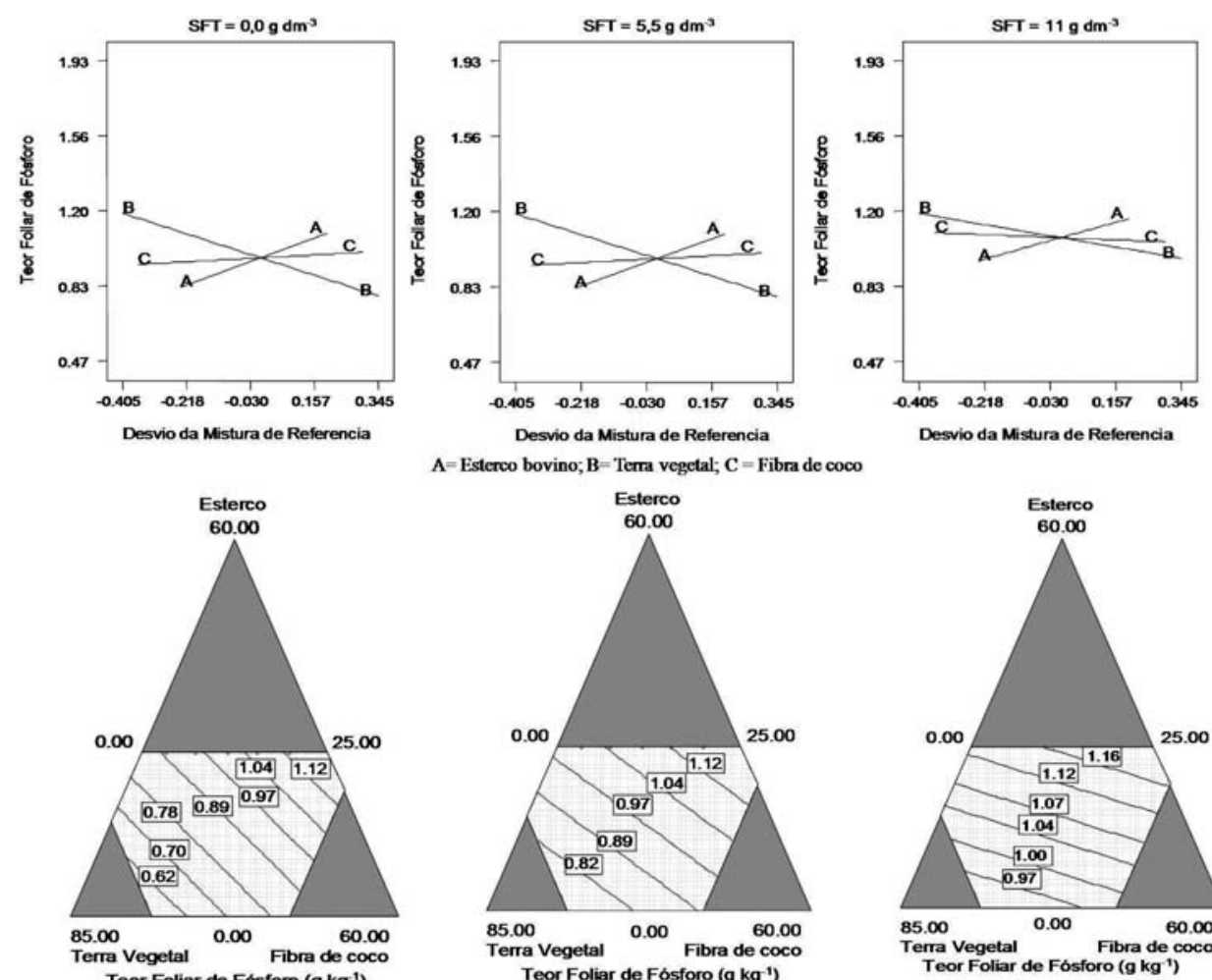

A= Esterco bovino; $\mathbf{B}=$ Terra vegetal; $\mathbf{C}=$ Fibra de coco
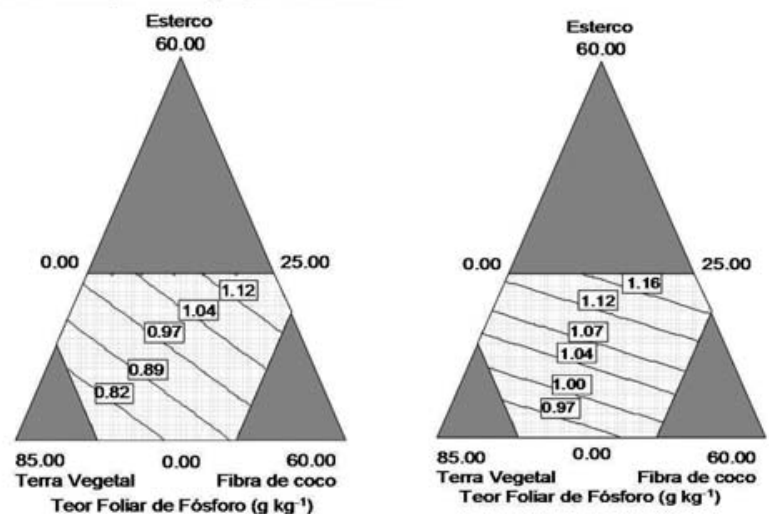

FIGURA 7 - Teor de fósforo nos tecidos foliares das mudas de mangabeira (Hancornia speciosa) em função dos diferentes componentes dos substratos.
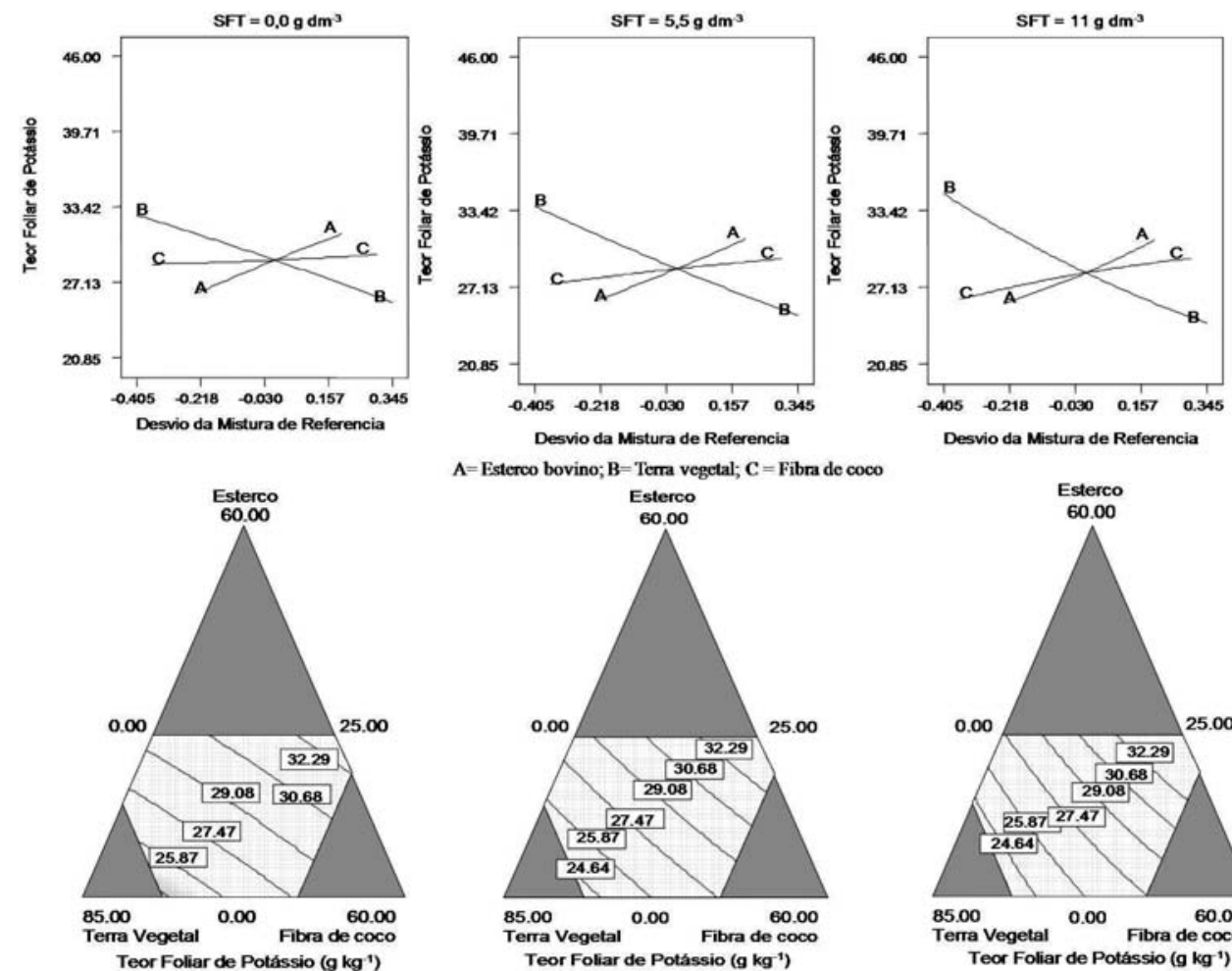

A $=$ Esteroo bovino; $B=$ Terra vegetal; $\mathbf{C}=$ Fibra de coco
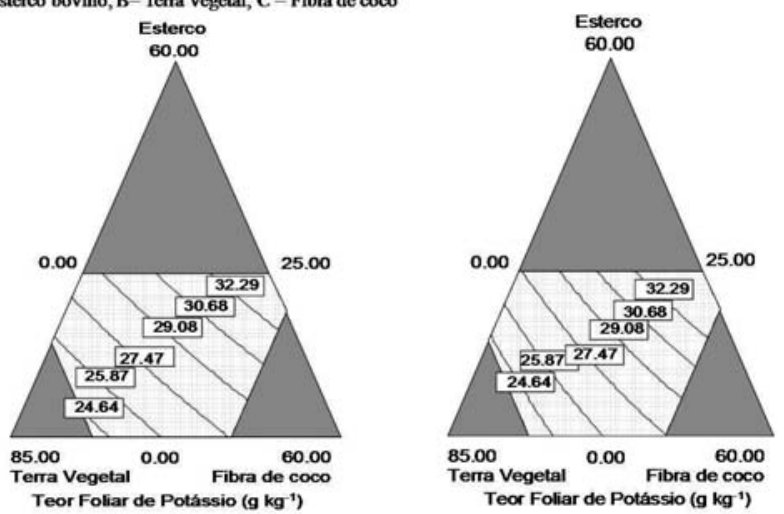

FIGURA 8 - Teor de potássio nos tecidos foliares das mudas de mangabeira (Hancornia speciosa) em função dos diferentes componentes dos substratos. 


\section{CONCLUSÕES}

1-As mudas de mangabeira apresentaram crescimento vegetativo e estado nutricional satisfatório nos substratos com maior proporção de terra vegetal e fibra de coco, associado à baixa proporção de esterco bovino no volume do substrato.

2-Doses elevadas de superfosfato triplo não exercem efeito benéfico sobre o crescimento das mudas de mangabeira, em substratos constituídos por terra vegetal, fibra de coco e esterco bovino.

3-Concentração elevada de esterco bovino na constituição do substrato provoca redução do desenvolvimento radicular, comprometendo a expansão foliar, devido à presença de fungos patogênicos, causadores de podridão radicular em mudas de mangabeira.

4-O substrato mais eficiente para o crescimento e a qualidade nutricional de mudas de mangabeira corresponde a $14 \%$ de esterco bovino, $56 \%$ de terra vegetal, $15 \%$ de fibra de coco, $15 \%$ de areia e $4 \mathrm{~g} \mathrm{dm}^{-3}$ de superfosfato triplo.

\section{REFERÊNCIAS}

ALMEIDA, C.C.S. Adubação com NPK em plantas jovens de mangabeira. Trabalho de Conclusão de Curso (Graduação em Agronomia). Universidade Federal de Alagoas. Maceió, 2000, 42p.

ALVES, R.E.; LEMOS, R.P.; OLIVEIRA, E.F.; SILVA, H.; SILVA, A.Q.; MALAVOLTA, E. Concentração de nutrientes na planta e nos frutos de mangabeira (Hancornia speciosa, Gomes) por ocasião da colheita. In: CONGRESSO BRASILEIRO DE FRUTICULTURA, 10. Fortaleza. Anais... Fortaleza: SBF, 1989, v.1, p.352-355.

BECKMAN-CAVALCANTE, M.Z. Caracteristicas de substrato e concentração de soluções nutritivas para o crisanto em vaso. 2007. Tese (Doutorado). USP. Fac. Ciências Agrárias e Veterinária, Jaboticabal - SP - Brasil, 2007. 145p.

BEZERRA, F.C.; ROSA, M.F. Pó da casca de coco verde como substrato para plantas. In: ENCONTRO NACIONAL DE SUBSTRATOS PARA PLANTAS, 3, 2002, Campinas: Caracterização, manejo e qualidade de substratos para produção de plantas. Campinas: IAC, 2002. p.94.
BONDARI, K. Mixture experiments and their applications in agricultural research. In: SAS ${ }^{\circledR}$ Users Group International Conference 30., 2005, Pennsylvania. Proceedings... Pennsylvania: SAS Institute Inc., 2005. p. 1-8. Disponível em: <http:// www2.sas.com/proceedings/sugi30/209-30.pdf $>$. Acesso em: 27 out. 2007.

CORNELL, J.A. Experiments with mixtures: designs, models, and the analysis of mixture data, 3.ed., Wiley: New York, 2001. 680p.

COSCIONE, A.R.; ANDRADE, J.C.; MAY, G.M. O modelamento estatístico de misturas: experimento tutorial usando voltametria de redissolução anódica. Química Nova, São Paulo, v. 28, n. 6, p. 1116-1122, 2005.

DIAS, L.E.; ALVAREZ, V.H.; KUCKSCH, I.; BARROS, N.F.; BRIENZA JUNIOR, S. Formação de mudas de táxi-branco (Sclerolobium paniculatum Voguel) reposta a calcário e fósforo. Pesq. Agropecuária Brasileira, Brasília, v.26, n. 1, p.69-76, 1991.

DIAS, T.J.; PEREIRA, W.E.; SOUSA, G.G. Fertilidade de substratos para mudas de mangabeira, contendo fibra de coco e adubados com fósforo. Acta Sci. Agron, Maringá, v. 29, supl., p. 649-658, 2007.

DONADIO, L.C.; MÔRO, F.V.; SERVIDONE, A.A. Frutas brasileiras. Jaboticabal: Novos Talentos, 2002. 288p.

EPSTEIN, E.; BLOOM, A.J. Nutrição mineral de plantas: princípios e perspectivas. Londrina: PLANTA, 2006. 403p.

ESPINDOLA, A.C.M. Aspectos de nutrição mineral da mangabeira (Hancornia speciosa Gomez). Tese (Doutorado em Botânica) - Universidade Federal Rural de Pernambuco. Recife: UFRPE, 1999. 88p.

ESPÍNDOLA,A.C.M.;ANDRADE, A.G.; SILVA, C.A.; SOUZA, G.V.B.; COSTA, J.P.V.; MOURA FILHO, G. Deficiência nutricional em mudas de mangabeira (Hancornia speciosa Gomez). Revista Ciência Agrícola, Rio Largo, v.5, p.67-81, 1998.

FERNANDEZ, J.R.C. Efeito de substratos, recipientes e adubação na formação de mudas de mangabeira (Hancornia speciosa Gomes) Dissertação (Mestrado em Agronomia) - Faculdade de Agronomia e Medicina Veterinária, Cuiabá, UFMT, 2002. 65 p. 
FERREIRA, E.G.; ARAÚJO, I.A.; SANTOS, E.S.; FRANCO, F.O.; MENINO, I.B. Diagnose em folhas e ramos de mangabeira do florescimento ao ponto de colheita. In: SIMPÓSIO BRASILEIRO SOBRE A CULTURA DA MANGABA, 2003, Aracaju-SE. Anais... Aracaju: Embrapa Tabuleiros Costeiros, 2003. 1 CD-ROM.

FERREIRA, E.G.; MARINHO, S.J.O. Produção de frutos da mangabeira para consumo in natura e industrializado. Tecnol. \& Ciên. Agropec., João Pessoa, v.1, n.1, p.9-14, 2007.

GUIMARÃES, C.M.; STONE, L.F.; MOREIRA, J.A.A. Compactação do solo na cultura do feijoeiro. II: Efeito sobre o desenvolvimento radicular e da parte aérea. Revista Brasileira de Engenharia Agrícola e Ambiental. vol. 6 n. 2. p.213-218. Campina Grande, 2002.

JUNQUERIA, N.T.V.; CHARCHAR, M.J.D.; PEREIRA, E.B.C.; PEREIRA, A.V. Principais doenças da mangabeira. In: SIMPÓSIO BRASILEIRO SOBRE A CULTURA DA MANGABA, 2003, Aracaju-SE. Anais... Aracaju: Embrapa Tabuleiros Costeiros, 2003. 1CD-ROM.

KIM, S.M. Surimi-alginate gels as affected by setting: a study based on mixture design and regression models. Food Res. Int., Toronto, v. 36, n. 3, p. 295302, 2003.

LEMOS, R.P.; ALVES, R.E.; OLIVEIRA, E.F.; SILVA, H.; SILVA, A.Q. Características pomológicas de mangabeira (Hancornia speciosa Gomes) da Paraíba. In: CONGRESSO BRASILEIRO DE FRUTICULTURA, 10, 1989, Fortaleza. Anais... Fortaleza: SBF, 1989. p. 346-351.

LÓPES-BUCIO, J.L.; HERNÁNDEZ-ABREU, E.; SÁNCHEZ-CALDERÓN, L.; NIETO-JABOCO M.F.; SIMPSON, J.; HERRERA-ESTRELLA, L. Phosphate availability alters architecture and causes changes in hormone sensitivity in the Arabidopsis root system. Plant Physiology, v. 109, p.244-256, 2002.

MALAVOLTA, E.; VITTI, G.C.; OLIVEIRA, S.A. Avaliação do estado nutricional das plantas: princípios e aplicações. Piracicaba: POTAFOS, 1997. 319p.

NIELSEN, K.L.; ESHEL, A.; LYNCH, J.P. The effect of $P$ availability on the carbon economy of contrasting common bean (Phaseolus vulgaris) genotypes.
Journal of Experimental Botany, v. 52, p.329-339, 2001.

NOGUEIRA, R.J.M.C.; ALBUQUERQUE, M.B. de.; SILVA JUNIOR, J.F. Efeito do substrato na emergência, crescimento e comportamento estomático em plântulas de mangabeira. Revista Brasileira de Fruticultura. v. 25, n.1, p. 15-18, 2003.

PEREIRA, E.B.C.; PEREIRA, A.V.; GOMES, A.C.; SOUSA SILVA, J.C.; Avaliação da composição do substrato para mudas de mangabeira em tubetes. Embrapa Cerrados (2003), Disponível em: $<\underline{\text { http:// }}$ bbeletronica.cpac.embrapa.br>. Acesso em: 09 nov. 2005.

ROSA, M.F.; SANTOS, J.S.S.; MONTENEGRO, A.A.T.; ABREU, F.A.P.; ARAÚJO, F.B.S.; NORÕES, E.R. Caracterização do pó da casca de coco verde usado como substrato agrícola. Fortaleza: Embrapa Agroindústria Tropical, 2001. 6p. (Comunicado Técnico, 5).

SILVA, D.B.; SILVA, J.A.; JUNQUEIRA, N.T.V.; ANDRADE, L.R.M. Frutas do cerrado. Brasília: Embrapa Informação Tecnológica, 2001. 179p.

SILVA, F.C. (Ed.). Manual de análises químicas de solos, plantas e fertilizantes. Brasília: EMBRAPA, 1999. 370p.

SILVA, H.; SILVA, A.Q.; CAVALCANTI, A.T.; MALAVOLTA, E. Composição mineral das folhas de algumas fruteiras do Nordeste. In: CONGRESSO BRASILEIRO DE FRUTICULTURA, 7., 1984. Florianópolis. Anais... Florianópolis: Sociedade Brasileira de Fruticultura. 1984, p. 320 - 325.

VENTURIN, N.; NOGUEIRA, F.D.; COQUEIRO, G.R. Efeito do fosfato de Araxá, calcário e gesso em mudas de seringueira (Hevea sp). Pesquisa Agropecuária Brasileira, Brasília, v. 30, n. 3, p. 187-193, 1995.

VIEIRA, F.C.S.; NAHAS, E. Microbial counts of dark red latosol samples stored at different temperatures. Revista de Microbiologia, São Paulo, v.29, p.159$163,1998$.

VIEIRA NETO, R.D. Recomendações técnicas para o cultivo da mangabeira. Aracaju: Embrapa Tabuleiros Costeiros, 2001, 20 p. (Embrapa Tabuleiros Costeiros. Circular Técnica, 20). 